\title{
Towards a recommendation system for the learner from a semantic model of knowledge in a collaborative environment
}

\author{
Chahrazed Mediani1 ${ }^{1}$, Marie-Hélène Abel $^{2}$, Mahieddine Djoudi ${ }^{3}$ \\ ${ }^{1}$ Laboratoire des réseaux et des système distribués, Département d'Informatique, Faculté \\ des sciences, Université Ferhat Abbas de Sétif -1-, Algérie \\ chahrazed mediani@yahoo.fr \\ ${ }^{2}$ Sorbonne universités, Université de technologie de Compiègne, France. \\ marie-helene.abel@utc.fr \\ ${ }^{3}$ Laboratoire XLIM-SIC et équipe TechNE, UFR Sciences SP2MI, \\ Université de Poitiers, France \\ mahieddine.djoudiduniv-poitiers.fr
}

\begin{abstract}
Collaboration is a common work between many people which generates the creation of a common task. A computing environment can foster collaboration among peers to exchange and share knowledge or skills for succeeding a common project. Therefore, when users interact among themselves and with an environment, they provide a lot of information. This information is recorded and classified in a model of traces to be used to enhance collaborative learning. In this paper, we propose (1) the refinement of a semantic model of traces with indicators calculated according to Bayes formulas and (2) the exploitation of these indicators to provide recommendations to the learner to reinforce learning points with learners, of his/her community of collaboration, identified as "experts".
\end{abstract}

Keywords: Collaboration, Trace, Indicator, Recommendation system.

\section{Introduction}

The advent of Information and Communication Technologies and particularly Web 2.0 technologies have facilitated learning based primarily on exchanges and resource sharing between learners of the same community (Abel, 2008). On its side, collaborative learning is a process leading to the progressive construction of knowledge. This learning derived from the current of constructivism allows a person to build knowledge from interaction with his surroundings. When these interactions are performed using digital technology, they leave traces. These traces are usually saved in a model of traces (Settouti et al., 2006) and thus made usable for various purposes such as updating a learner model. Taking account the learner activities within a Computing Environment for Human Learning (CEHL) to guide him in his learning is complex. The learner model allows to consider knowledge of all kinds (preferences, motivations, acquired knowledge or not, mistakes, etc.). As part of our work, we focus on the 
interactions between learners via a CEHL and with a CEHL to make recommendations to guide learner in their learning. To this end, we have chosen to characterize a number of actions that a learner can perform in a CEHL to define learning indicators to establish recommendations. Learning is the result of personal and collaborative actions. We therefore consider the traces resulting of these two axes.

To do this, we have chosen to refine the collaboration model of traces proposed by (Wang et al, 2014) and illustrated in the environment E-MEMORAe 2.0 (Abel, 2009). So we have introduced measures to estimate some parameters, unmeasurable and unobservable by observable indicators describing the state of the learner activities and the progression of his knowledge when interacting within a community of learners.

In the following, we state our problem before presenting the limitations of existing work related to measures established to make recommendations to learners. We then detail our approach based on a model of traces increased by indicators and its exploitation through a case study before concluding and advancing the prospects for this work.

\section{Motivation}

The Information and Communication Technologies and the emergence of collaborative learning platforms have enabled the implementation of collaborative CEHL and related issues such as the lack of information on the learner evolution within the community and the state of his knowledge and his activities in his group. This information is needed to measure the contribution of each member in the community and may be useful in defining the responsibilities of each member of the group. This information is also useful for the learner himself; this allows him to have a state of his learning and to allow him to prepare himself for a more relevant evaluation. To remedy these problems, the analysis of the leaner interaction traces with a learning environment has become a research topic that is rapidly evolving.

\section{$3 \quad$ Related work}

In the context of CEHL, trace-based study is not just about how to analyze the traces but also how to complete them and exploit them to improve learning (OllagnierBelbame et al., 2007). Among the works that have been done in the context of CEHL to support observation, we can mention the work treating the analyzing of the learner behavior and the characterization of his activities (Georgeon et al., 2006), and those that treat the interpretation of learner interactions with computing environments and with other users (Siebra et al., 2005), (George, 2004). There are several learning environments where interactions between the system and users are traced, we mention, for example: the collaborative learning environment Drew (Dialogical Reasoning Educational Web tool) (Corbel and al., 2002). COLAT tool (Collaboration Analysis Tool) (Avouris et al., 2004) is an independent tool for any learning system for the analysis of collaborative activities from the log files and video recordings. Recently, much work has been done to automate, acquire and distribute knowledge. For example, 
AdaLearn (Alian Al-Akhras and 2010) is an adaptive learning environment that saves learner responses in his profile to latter allow to direct him through recommendations. (Sani et al., 2012) propose an ontology-based architecture to model the learner and adapt learning styles to learners' profiles. (Li et al., 2012) define an original traces model that distinguishes private actions, individual, collective and collaborative. (Wang et al. 2014) define a method to exploit this model based on TF-IDF method to calculate the index of competence of each learner on a given knowledge. This calculation takes into account the activities of the learner about the knowledge in question, but it does not take into account the acquisition of the knowledge. Under this model, a learner can be proficient in knowledge without being proficient in the knowledge that characterizes it.

\section{Our Approach}

Our approach is to refine the collaborative model of traces of (Li et al., 2012), and taken up by (Wang et al, 2014), by a number of measures to build indicators on the state of the learner knowledge and the progression of his knowledge within a group in a learning session. Among These parameters: we retain the mastery degree of knowledge represented by a concept. To achieve these goals, we have adopted the following approach: (i) propose a semantic model to measure indicators of the contribution of each student in the group, (ii) estimate the contribution of indicators using Bayesian formulas (Triola 2010), this contribution should take into account the knowledge of the learner and his activities, (iii) propose a set of recommendations to assist the learner in his learning and prepare him for a more appropriate evaluation.

As shown in Figure 1, the architecture of the recommendation system that we propose is composed of two modules operating three models: a trace collection module, a pedagogical content model, a learner model, a collaboration model and a recommendation module. This system is used to collect traces of users and store them in a database of traces. A trace is a time sequence of observed containing all user actions to perform a given task.

The first module of our system treats the collecting primary traces in native format. The second module classifies the primary traces coming from the first module as high-level traces along the trace model (Li, 2013). Depending on the content of traces model and pedagogical content model, algorithms for learning indicators calculations of the learner are applied in the recommendation module. For that, the recommendation system must select good recommendations that guide the user in achieving his learning task. We will illustrate this system of recommendations within the collaborative learning platform E-MEMORAe 2.0 (Abel and Leblanc, 2009).

In the next subsections, we present the principle of the main components of the recommendation system, namely the pedagogical content model, collaborative model, collection of traces and the learner model. The calculation of learning indicators and the recommendation module will be presented in the following sections. 


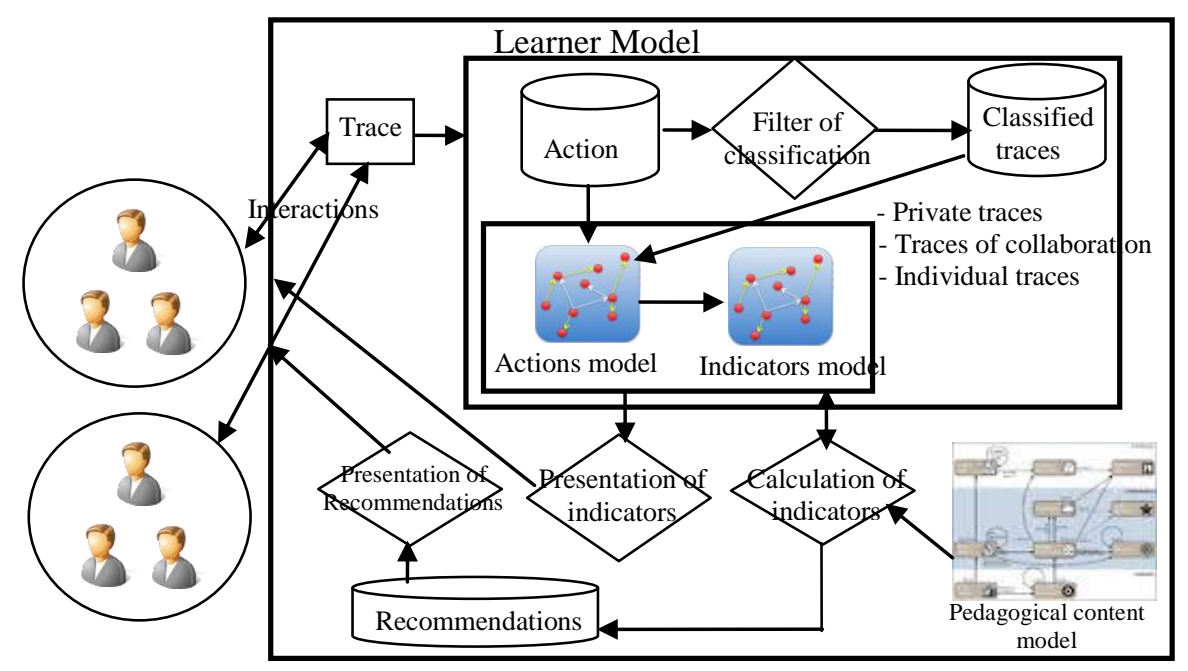

Fig. 1. Architecture of the recommendation system

\subsection{Pedagogical content model}

The content model of learning environments usually consists of a set of elements representing elementary fragments of domain knowledge studied. These elements, often organized in a hierarchy, are named (concepts, notions, knowledge elements, subjects) and they can be of different types. Our content model consists of application ontologies. The application ontology specifies the concepts of a particular application. These concepts represent concepts to be learned of a training unit. A concept is therefore a particular concept that needs to be assimilated by the learner during learning. The concepts are used to index the pedagogical resources treating them. This provides a way to reuse these resources. These concepts are organized in a hierarchy that also represents several types of relationships (specialization and others). Among the ontologies of applications built as part of the E-MEMORAe 2.0 environment: Ontology for the teaching unit "Information Technology". For these applications ontologies, we propose to add the attribute "weight" to the relationship of type "is a" between each concept and its sub concepts $(0<=$ weight $<=1)$ with the sum of the weights of subconcepts equal to 1 . This value is determined by the responsible of training and represents the degree of contribution of this concept in the acquisition of the father concept (Figure 2).

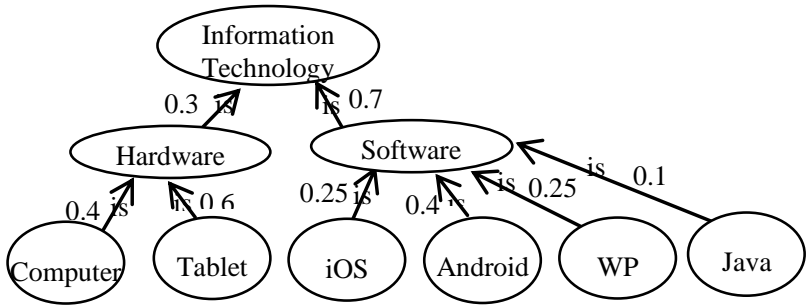

Fig. 2. Part of the application ontology "Information Technology" 


\subsection{Collaboration model}

Our model allows organizing collaborative spaces for students working in groups on the same problem. Thus forming a work site and exchange for the group and allowing, on the one hand, to each member of the group to access resources (documents and other) for the group and, on the other hand, to memorize his work (documents, ideas, knowledge, solutions, etc.) on the Treaty problem. The MEMORAe 2.0 environment allows each user to choose to access a private space or spaces of groups to which he belongs.

- The private space: space where each user can set his own resources. The content of this space is accessible only by that user.

- Space group: space is only accessible by members of the group and in which they share and exchange resources.

\subsection{Collect of traces}

The traces collection is to observe the student in a learning situation and memorize his activities traces to infer the learner model. This collection mode is interesting because it captures the learner interaction the learner without distracting him from his main task. In E-Memorae2.0, these actions are stored in the database traces and classified according to the actions model of the E-MEMORAe 2.0 platform. According to this model, we have three types of traces: Private traces belonging to the private space, traces of collaboration that belong to the space of collaboration and individual traces that are private traces and traces of collaboration. For each type of traces, we have three types of activities that can be conducted by the learner: learning resources consultations (documents), resources creation (conversations, meetings, questions, answers, notes and wikis) and resources additions (documents and annotations).

Example: Figure 3 shows an example of interaction on different concepts, of a group of users using a histogram. Each line represents the collaboration traces of a user for each concept.

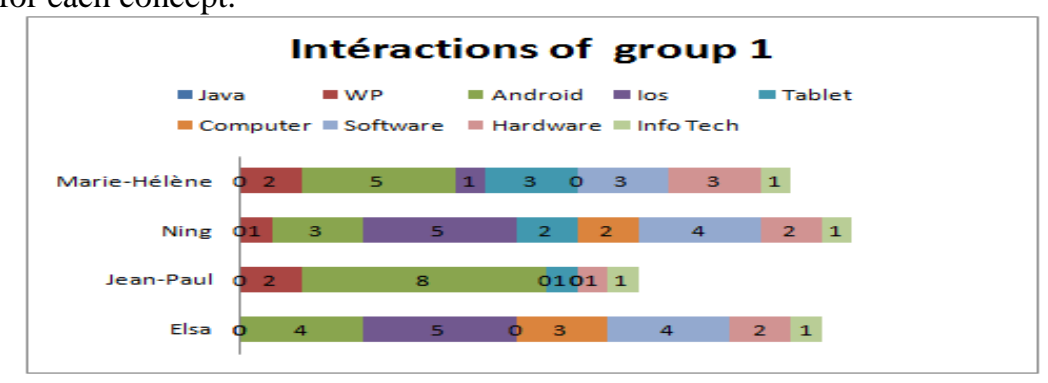

Fig. 3. Example of collaborative interactions in a group

The following table summarizes the actions, of figure 2, performed by members of the group 1. For a given concept, each cell of the table represents the number of actions performed by the learner for each type of activity (C: Consultation, R: Creation, A: 
Addition). The number before the parenthesis is the sum of the learner actions for the concept.

Table 1. Summary of users' actions of group 1

\begin{tabular}{|c|c|c|c|c|c|}
\hline & Elsa & Jean-Paul & Ning & Marie-Hélène & Total \\
\hline Java & $0(0 \mathrm{C}, 0 \mathrm{R}, 0 \mathrm{~A})$ & $0(0 \mathrm{C}, 0 \mathrm{R}, 0 \mathrm{~A})$ & $0(0 \mathrm{C}, 0 \mathrm{R}, 0 \mathrm{~A})$ & $0(0 \mathrm{C}, 0 \mathrm{R}, 0 \mathrm{~A})$ & $\mathbf{O}(\mathbf{0 C}, \mathbf{0 R}, \mathbf{0 A})$ \\
\hline WP & $0(0 \mathrm{C}, 0 \mathrm{R}, 0 \mathrm{~A})$ & $2(1 \mathrm{C}, 1 \mathrm{R}, 0 \mathrm{~A})$ & $1(0 \mathrm{C}, 0 \mathrm{R}, 1 \mathrm{~A})$ & $2(0 \mathrm{C}, 1 \mathrm{R}, 1 \mathrm{~A})$ & $5(1 C, 2 R, 2 A)$ \\
\hline Android & $4(1 \mathrm{C}, 3 \mathrm{R}, 0 \mathrm{~A})$ & $8(4 \mathrm{C}, 3 \mathrm{R}, 1 \mathrm{~A})$ & $3(1 \mathrm{C}, 1 \mathrm{R}, 1 \mathrm{~A})$ & $5(4 \mathrm{C}, 1 \mathrm{R}, 0 \mathrm{AS})$ & $20(10 C, 8 R, 2 A)$ \\
\hline Ios & $5(2 \mathrm{C}, 1 \mathrm{R}, 2 \mathrm{~A})$ & $0(0 \mathrm{C}, 0 \mathrm{R}, 0 \mathrm{~A})$ & $5(2 \mathrm{C}, 2 \mathrm{R}, 1 \mathrm{~A})$ & $1(0 \mathrm{C}, 0 \mathrm{R}, 1 \mathrm{~A})$ & 11(4C,3R,4A) \\
\hline Tablet & $0(0 \mathrm{C}, 0 \mathrm{R}, 0 \mathrm{~A})$ & $1(0 \mathrm{C}, 1 \mathrm{R}, 0 \mathrm{~A})$ & $2(1 \mathrm{C}, 0 \mathrm{R}, 1 \mathrm{~A})$ & $3(0 \mathrm{C}, 2 \mathrm{R}, 1 \mathrm{~A})$ & $6(1 \mathrm{C}, 3 \mathrm{R}, 2 \mathrm{~A})$ \\
\hline Computer & $3(2 \mathrm{C}, 0 \mathrm{R}, 1 \mathrm{~A})$ & $0(0 \mathrm{C}, 0 \mathrm{R}, 0 \mathrm{~A})$ & $2(0 \mathrm{C}, 0 \mathrm{R}, 2 \mathrm{~A})$ & $0(0 \mathrm{C}, 0 \mathrm{R}, 0 \mathrm{~A})$ & $5(2 \mathrm{C}, 0 \mathrm{R}, 3 \mathrm{~A})$ \\
\hline Software & $4(2 \mathrm{C}, 1 \mathrm{R}, 1 \mathrm{~A})$ & $0(0 \mathrm{C}, 0 \mathrm{R}, 0 \mathrm{~A})$ & $4(1 \mathrm{C}, 2 \mathrm{R}, 1 \mathrm{~A})$ & $3(1 \mathrm{C}, 1 \mathrm{R}, 1 \mathrm{~A})$ & $11(4 C, 4 R, 3 A)$ \\
\hline Hardware & $2(1 \mathrm{C}, 1 \mathrm{R}, 0 \mathrm{~A})$ & $1(0 \mathrm{C}, 1 \mathrm{R}, 0 \mathrm{~A})$ & $2(1 \mathrm{C}, 0 \mathrm{R}, 1 \mathrm{~A})$ & $3(0 \mathrm{C}, 2 \mathrm{R}, 1 \mathrm{~A})$ & $8(2 C, 4 R, 2 A)$ \\
\hline Info_Tech & $1(1 \mathrm{C}, 0 \mathrm{R}, 0 \mathrm{~A})$ & $1(1 \mathrm{C}, 0 \mathrm{R}, 0 \mathrm{~A})$ & $1(1 \mathrm{C}, 0 \mathrm{R}, 0 \mathrm{~A})$ & $1(1 \mathrm{C}, 0 \mathrm{R}, 0 \mathrm{~A})$ & $4(4 \mathrm{C}, 0 \mathrm{R}, 0 \mathrm{~A})$ \\
\hline Total & $19(9 \mathrm{C}, 6 \mathrm{R}, 4 \mathrm{~A})$ & $13(6 \mathrm{C}, 6 \mathrm{R}, 1 \mathrm{~A})$ & $20(7 C, 5 R, 8 A)$ & $18(6 \mathrm{C}, 7 \mathrm{R}, 5 \mathrm{~A})$ & $60(28 \mathrm{C}, 24 \mathrm{R}, 18 \mathrm{~A})$ \\
\hline
\end{tabular}

$\mathbf{C}$ : Consultation, $\mathbf{R}$ : Creation, $\mathbf{A}$ : Addition.

\subsection{Learner model}

Our learner model is a subset of the pedagogical content model. The pedagogical content is decomposed into a set of elements and the learner model is represented by a set of measurable values associated to these elements. These values vary between 0 (not mastered) and 1 (mastered). The structure of the learner model is the same as the Bayesian network (Figure 4). The elements (concepts and activities) of the learner model become nodes in the Bayesian network. The weight of each element is replaced, for each variable, by a probability to estimate the mastery degree of the learner knowledge. These probabilities vary between 0 (not mastered) and 1 (mastered). The relationship of type "is-a" in the learner model become conditional dependencies between variables forming arcs of the Bayesian network. The elements of knowledge or concepts represent unobservable variables while other elements which are the learning activities used to measure the mastery degree of the learner knowledge (tests, exercises, forums, etc.), represent the observable variables which are added to the Bayesian network.

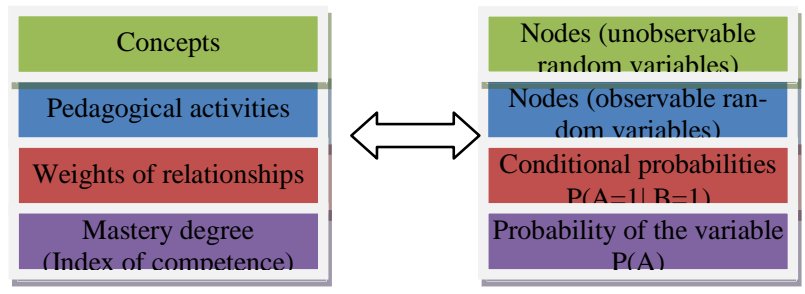

Fig. 4. Relationship between our learner model and a Bayesian network. 


\section{Construction of the learner model from indicators}

For a given concept, we aim to measure the degree of mastery of this concept by the learner from the activities related to the concept which he conducted in his group space (contribution by activities) and also from the knowledge acquired by navigating the sub concepts and implementation of activities related to his sub-concepts (contribution by the sub-knowledge). For each concept, we assign a weight P1 to the contribution activities and a weight $\mathrm{P} 2$ to the contribution by the sub-concepts. The sum of these weights must be equal to one.

Example: $\mathrm{P} 1=0.6, \mathrm{P} 2=0.4$.

Each concept is linked to a set of activities, so we can estimate the degree of the learner contribution based on the number of the learner activities carried out in his group. We assign to each type of activity a weight (parameter) which represents the degree of contribution of his activities in the calculation of the mastery degree of this concept by the learner. This setting can distinguish concepts that require a more theoretical activity (consultation) from practical (realization of an exercise, creating a resource). The sum of the weights of the types of activities should be equal to one.

Example: For a given concept, Poids_consultation $=0.2$, Poids_création $=0.5$ and Poids_addition $=0.3$. (These weights can vary from one concept to another).

To realize our contribution model, we use the format of Resource Description Framework (RDF). RDF graph is a model that is used to formally describe Web resources and metadata. Figure 5 shows the RDFS graph of our knowledge model. An ellipse is a class resources and a rectangle represents a property.

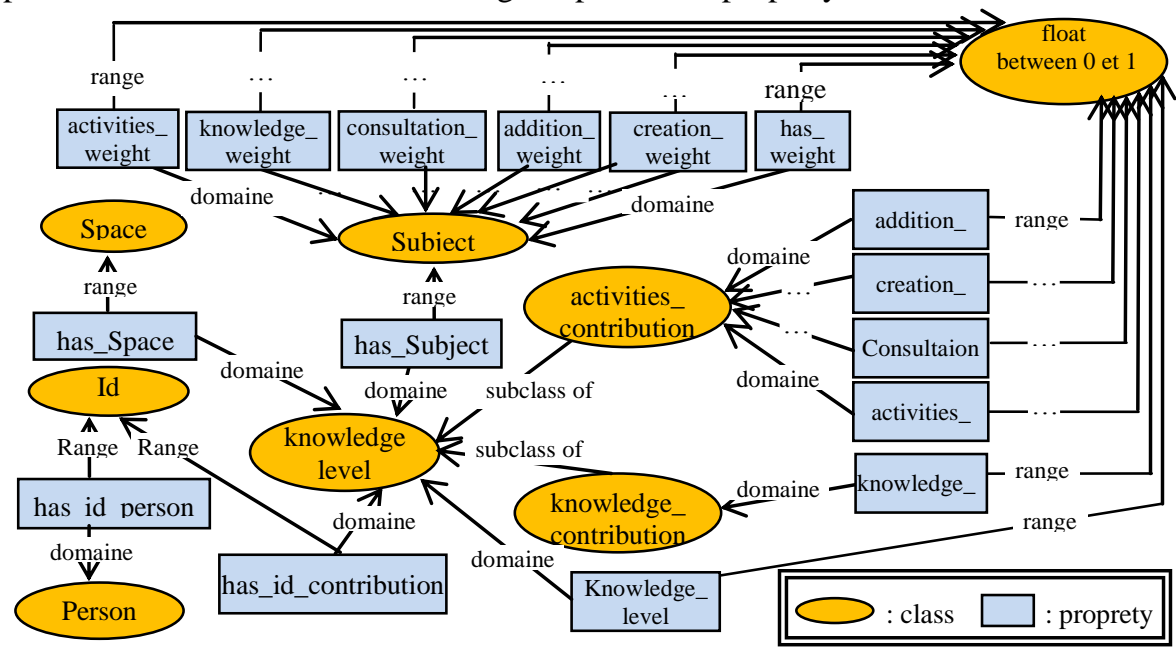

Fig. 5. The knowledge model in the platform E-MEMORAe 2.0

\subsection{Indicators calculation}

To measure learning indicators (mastery degree of a concept, degree of contribution by activities, degree of contribution by the sub concepts), of the learner in his space 
group, we apply Bayesian formula. The Bayesian network is a probabilistic technique that has been developed in the research context to describe the uncertainty of facts in artificial intelligence. Bayesian networks allow easy representation of causal relationships in the learner model. Generally, the learner model information is related to each other. In other words, the learner's knowledge affects each other, for example, motivation to learn, has a direct influence on the ability to perform the task. And as the student model has an hypothetical character, using probabilities, uncertainty is processed. The calculation we retain is based on the following formula:

Consider a partition $A_{1}, A_{2}, \ldots, A_{n}$ of the set $E$ of events: $A_{1} \cup A_{2} \cup \ldots \cup A_{n}=E$, $A_{i} \cap A_{j}=\varnothing$ for $i \neq j, P(E)=1$. For any event $B$ :

$\mathrm{P}(\mathrm{B})=\mathrm{P}\left(\mathrm{A}_{1}\right) \cdot \mathrm{P}\left(\mathrm{B} \mid \mathrm{A}_{1}\right)+\mathrm{P}\left(\mathrm{A}_{2}\right) \cdot \mathrm{P}\left(\mathrm{B} \mid \mathrm{A}_{2}\right)+\ldots+\mathrm{P}\left(\mathrm{A}_{\mathrm{n}}\right) . \mathrm{P}\left(\mathrm{B} \mid \mathrm{A}_{\mathrm{n}}\right)$.

$\mathrm{P}(\mathrm{B} \mid \mathrm{A})$ : the conditional probability that event $\mathrm{B}$ is true given that the event $\mathrm{A}$ is already true. We apply equation (1) to calculate the previous indicators.

\section{The contribution by the activities.}

For a learner $i$ in a space $S$, the index of the contribution by activities $A C(i, j)$ for a concept $\mathrm{j}$ is calculated as follows:

$$
\mathrm{AC}(\mathrm{i}, \mathrm{j})=\sum_{k=1}^{n} P(k) * \text { contribution_value }(\mathrm{k})
$$

With $n$ : the number of types of activities, in our case $n=3$. $P(k)$ : the weight of the type of activity $\mathrm{k}$ (consultation, creation or addition), contribution_value(k) : is relative frequency estimated by the ratio between the number of activities of type k performed by the learner in the group and the number of all activities of type k performed by all the members of the group S. contribution_value is either consultation_value, creation_value or addition_value.

Example: for the concept "Android", suppose that: Poids_consultation $=0.2$, Poids_création $=0.5$ and Poids addition $=0.3$. Using table 1 , we calculate the contribution by the activities of the members of group 1 for this concept (Table 2).

Table 2. Contributions by the activities of the users of group1 for "Android".

\begin{tabular}{|l|l|l|l|l|}
\hline & $\begin{array}{c}\text { Consulta- } \\
\text { tion_value }\end{array}$ & $\begin{array}{c}\text { Crea- } \\
\text { tion_value }\end{array}$ & $\begin{array}{c}\text { Addi- } \\
\text { tion_value }\end{array}$ & \multicolumn{1}{c|}{ Activities_value } \\
\hline Elsa & $1 / 10=0.1$ & $3 / 8=0.375$ & $0 / 2=0$ & $0.1 * 0.2+0.375 * 0.5+0 * 0.3=0.1975$ \\
\hline Jean-Paul & $4 / 10=0.4$ & $3 / 8=0.375$ & $1 / 2=0.5$ & $0.4 * 0.2+0.375 * 0.5+0.5 * 0.3=0.4175$ \\
\hline Ning & $1 / 10=0.1$ & $1 / 8=0.125$ & $1 / 2=0.5$ & $0.1 * 0.2+0.125 * 0.5+0.5 * 0.3=0.2325$ \\
\hline Marie-Hélène & $4 / 10=0.4$ & $1 / 8=0.125$ & $0 / 2=0$ & $0.4 * 0.2+0.125 * 0.5+0 * 0.3=0.1425$ \\
\hline
\end{tabular}

We calculate the contribution by activities of Marie-Hélène for all the concepts.

Table 3. Contributions by the activities of "Marie-Hélène" for all the concepts.

\begin{tabular}{|l|l|l|l|l|l|l|l|l|l|}
\hline & Java & WP & Android & Ios & Tablet & Computer & Software & Hardware & Info_Tech \\
\hline $\begin{array}{l}\text { Marie- } \\
\text { Hélène }\end{array}$ & 0 & 0.4 & 0.142 & 0.075 & 0.483 & 0 & 0.274 & 0.4 & 0.05 \\
\hline
\end{tabular}




\section{The contribution by sub-knowledge .}

For a learner $i$, the index of contribution by sub-knowledge for a concept $\mathrm{j} K C(\mathrm{i}, \mathrm{j})$ is equal to:

$$
\mathrm{KC}(\mathrm{i}, \mathrm{j})=\sum_{k=1}^{n} P(k) * \text { knowledge_level }(\mathrm{k})
$$

$\mathrm{n}$ is the number $\mathrm{k}$ of the sub-concepts related to the father concept $\mathrm{j}$. P $(\mathrm{k})$ : the weight attached to each sub-concept $\mathrm{k}$. (These weights are defined in the ontology of application).

Example: The concept "Android" has no sub concepts thus:

$$
\mathrm{KC}(\text { Marie-Hélène, Android })=0
$$

\section{The Global contribution (mastery degree).}

Now, the mastery degree or the knowledge level of the learner $i$ on the concept $j$ $\mathrm{KL}(\mathrm{i}, \mathrm{j})$ is equal to:

$$
\mathrm{KL}(\mathrm{i}, \mathrm{j})=\mathrm{P} 1 * \mathrm{AC}(\mathrm{i}, \mathrm{j})+\mathrm{P} 2 * \mathrm{KC}(\mathrm{i}, \mathrm{j})
$$

$\mathrm{P} 1$ and P2 are the weights connected to both contributions (activities_contribution and knowledge_contribution respectively).

Example: The concept "Android" has no sub-concept. So the only contribution for this concept is the contribution by activities $(\mathrm{P} 1=1, \mathrm{P} 2=0)$.

$\mathrm{KL}($ Marie-Hélène, Android) $=\mathrm{P} 1 * \mathrm{AC}$ (Marie-Hélène, Android) $+\mathrm{P} 2 * \mathrm{KC}$ (Marie-Hélène, Android)

$\mathrm{KL}_{\text {(Marie-Hélène, Android) }}=1 * 0.1425+0 * 0=0.1425$

Table 5 summarizes Marie-Hélène mastery levels for high-level concepts.

Table 4. Knowledge levels of "Marie-Hélène" for the sub-concepts.

\begin{tabular}{|l|l|l|l|l|l|l|}
\hline & Java & WP & Android & Ios & Tablet & Computer \\
\hline Marie-Hélène & 0 & 0.4 & 0.142 & 0.075 & 0.483 & 0 \\
\hline
\end{tabular}

Now, we will infer the mastery degree of Marie-Hélène for the concepts Software, Hardware and Information Technology. Suppose, for these concepts, the weight attached to activities $\mathrm{P} 1=0.6$ and the weight attached to the sub-concepts $\mathrm{P} 2=0.4$.

$\mathrm{KL}_{(\text {Marie-Hélène, Software) }}=\mathrm{P} 1 * \mathrm{AC}_{(\text {Marie-Hélène, Software) }}+\mathrm{P} 2 * \mathrm{KC}_{\text {(Marie-Hélène, Software) }}$

By applying equation (3):

$$
\mathrm{KC}_{\text {(Marie-Hélène, Software) }}=0.25 * 0.075+0.4 * 0.142+0.25 * 0.4+0.1 * 0=0.159
$$

Applying equation (4) :

$$
\mathrm{KL}_{\text {(Marie-Hélène,Software) }}=0.6 * 0.274+0.4 * 0.159=0.228
$$

Table 5 summarizes Marie-Hélène mastery levels for high-level concepts.

Table 5. Knowledge levels of "Marie-Hélène" for high-level concepts.

\begin{tabular}{|l|l|l|l|}
\hline & Software & Hardware & Information Technology \\
\hline Marie-Hélène & 0.228 & 0.356 & 0.119 \\
\hline
\end{tabular}




\section{The recommendation module}

The objective is to generate recommendation knowledge to the learner about his learning path from learning indicators stored in the indicators model. A recommendation $\mathrm{R}$ consists of an action proposal to achieve.

-u: the traced user.

$$
\mathrm{R}=\left\langle\mathrm{u}, \mathrm{s}, \mathrm{c}, \operatorname{tas} k,\left(\mathrm{o}_{1}, \mathrm{o}_{2}, \ldots, \mathrm{o}_{\mathrm{n}}\right)\right\rangle
$$

- s: the workspace.

- $\mathrm{c}$ : the concept concerned by the recommendation.

- task: the task we have to recommend the user to do it. It is either consult resources, add resources, create resources or consult other concepts.

- $(\mathrm{o} 1, \mathrm{o} 2, \ldots, \mathrm{on})$ : all users of the space $\mathrm{s}$ that can help the user $\mathrm{u}$ in achieving the task task.

\section{Recommendation algorithm.}

Input: Indicators model, P: Person, S: Space, C: Concept, $\varepsilon$ : threshold between 0 and 1/n (n: number of members of the group). RB : Recommandations Base.

Output: Recommendations Knowledge.

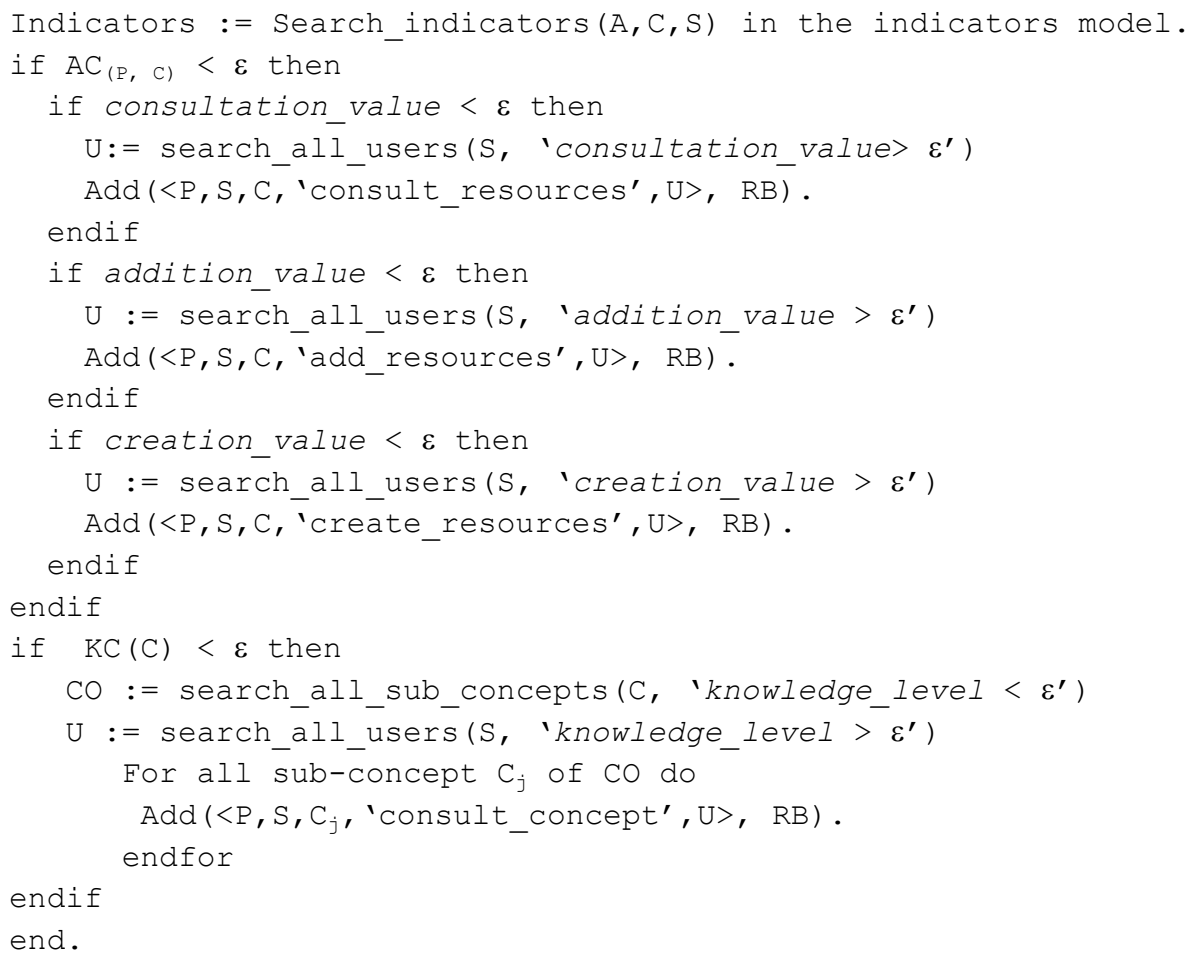

According to our model, if the mastery degree of a concept is below a certain threshold. Our algorithm can determine if this is due to the fact that the student has not 
achieved enough of activities in his workspace. If this is the case, the algorithm also determines if it is consultation, addition or creation activities. And in this case, he recommends the learner to perform more activities and provides a list of students in his group identified as "experts" that can assist him in the implementation of these activities. The algorithm can also determine if the problem is due to the lack of mastery of one or more sub-concepts and in this case, the algorithm recommends the learner to work more on these sub-concepts with learners who have already acquired skills for these sub-concepts.

\section{Discussion}

Our approach allows measuring some learning indicators such as the mastery level, of a concept by a learner, which is calculated according to the different activities that he has carried out within a group (collaboration space) on the concept and its sub concepts.

Returning to the previous example, we calculated the learning indicators of MarieHélène, within the group 1 composed of four members, for each concept of the application ontology that contains the concepts to be learned of a training unit. If we apply the recommendation algorithm to Marie-Hélène on the concept "Information Technology" with a threshold of $0.25(1 / 4)$, we obtain:

$\mathrm{KL}_{\text {(Marie-Hélène InfTech) }}=0.119<0.25$

We have: $\mathrm{AC}_{\text {(Marie-Hélène, InfTech) }}=0.05$ (consultation_value $=0.25$, creation_value $=$ 0 , addition_value $=0$ ). Marie-Hélène will be recommended to work on creating and adding resources with members of his group productive on these actions.

$\mathrm{KC}_{\text {(Marie-Hélène InfTech) }}=0.3 * 0,356+0.7 * 0,228=0,227<0.25$

The recommendation also focuses on sub concepts.

$\mathrm{KL}_{\text {(Marie-Hélène Software) }}=0.228<0.25$ and $\mathrm{KL}_{\text {(Marie-Hélène, Hardware) }}=0.356>0.25$

The work should be done especially on the sub-concept Software.

Let us now apply the recommendation algorithm to Marie-Hélène on the concept Software with the same threshold, we get:

$\mathrm{AC}_{\text {(Marie-Hélène, Software) }}=0.274>0.25$ and $\mathrm{KC}_{\text {(Marie-Hélène Software) }}=0.159<0.25$

Marie-Hélène must therefore be recommended to work on the sub-concepts of Software with learners who have already had expertise on these sub concepts.

We have: $\mathrm{KL}_{\text {(Marie-Hélène, Java) }}=0<0.25, \mathrm{KL}_{\text {(Marie-Hélène, } \mathrm{WP} \text { ) }}=0.4>0.25, \mathrm{KL}_{\text {(Marie-Hélène, }}$ Android) $=0.1425<0.25, \mathrm{KL}_{\text {(Marie-Hélène, Ios) }}=0.075<0.25$.

These sub-concepts are: Java, Android and Ios.

\section{Conclusion}

The traces are very important elements in collaborative environments. Their analysis aims to understand and follow the learning of a learner or group of learners and qualify the use, usability and acceptability of collaborative environment to make it more adaptive. In this paper, we proposed an architecture for a recommendation system for the learner. This architecture is based on an original model of the learner tak- 
ing into account the definition of data (learning indicators). A knowledge base containing this information was constructed. Interaction data recorded were used to construct indicators of learners' state, group state and the progression of the training session. The absence of such indicators in current learning and teaching environments has allowed us to justify our work. We have chosen to use a Bayesian formula to calculate the knowledge level of a learner on a concept of the application ontology describing the pedagogical content of training.

We are currently working to deploy the recommendation module within the environment E-MEMORAe2.0 in order to test it with students from the University of Setif.

\section{References}

1. Abel, M.H.: Apport des Mémoires Organisationnelles dans un contexte d'apprentissage. mémoire d'habilitation à diriger des recherches, université de technologie de Compiègne (2008)

2. Abel, M.H., Leblanc, A.: Knowledge Proc of sharing via the E-EMORAe2.0 platform. In the International Conference on Intellectual Capital, Knowledge Management \& Organizational Learning ,10-19 (2009)

3. Avouris, N., Komis, V., Margaritis, M., Fiotakis, G.: An environment for studying collaborative learning Activities. Educational Technology \& Society, 7(2), 34-41(2004)

4. Corbel, A., Girardot, J.J., Jaillon, P.: DREW : A Dialogical Reasoning Web tool. The International Conference on Information and Communication Techonologies in Education (ICTE). Badajoz, Spain , 20-23 November (2002)

5. George, S.: Analyse automatique de conversations textuelles synchrones d'apprenants pour la détermination de comportements sociaux. Revue Sciences et technologies de l'information et de la communication pour l'éducation et la formation (STICEF) Numéro spécial : technologies et formation à distance, 165-193 (2004)

6. Georgeon, O., Mille, A., Bellet, T.: Abstract : un outil et une méthodologie pour analyser une activité humaine médiée par un artefact technique complexe. Ingénierie des Connaissances IC 2006, Nantes, (2006)

7. Li, Q., Abel, M.H., Barthès, J.P.: Facilitating Experience Groups Sharing Collaborative Trace. Proceeding of Reuse Exploitation. and In International Conference on Knowledge Management and Information Sharing, 21-30 (2012)

8. Ollagnier-Beldame, M., et Mille, A.: Faciliter l'appropriation des EIAH par les apprenants via les traces informatiques d'interactions. Sticef spécial traces, (2007)

9. Sani, M. R. F., Mohammadian, N., Hoseini, M.: Ontological learner modeling. Procedia Social and Behavioral Sciences, 46, 5238 - 5243(2012)

10. Settouti, L., Prié, Y., Mille, A., Marty, J-C.: Système à base de traces pour l'apprentissage humain. Colloque international TICE 2006, Technologies de l'Information et de la Communication dans l'Enseignement Supérieur et l'Entreprise, (2006)

11. Siebra, S., Salgado, A.C., Brézillon, P., Tedesco, P.: A learning interaction memory using contextual information. The CONTEXT-05 Workshop on Context and Groupware, Paris, France, (2005)

12. Triola, M. F.: Baye's Theorem. Pearson education, (2010)

13. Wang, N., Abel, M.H., Barthès, J.P., Negre, E.: Towards a Recommender System from Semantic Traces for Decision Aid. KMIS, Rome, October (2014) 